\title{
Kerma conversion factors for modern glass buildings in radioactively contaminated areas
}

Hinrichsen, Yvonne; Andersson, Kasper Grann

Published in:

Journal of Radiological Protection

Link to article, DOI:

10.1088/1361-6498/aaf6ca

Publication date:

2019

Document Version

Peer reviewed version

Link back to DTU Orbit

Citation (APA):

Hinrichsen, Y., \& Andersson, K. G. (2019). Kerma conversion factors for modern glass buildings in radioactively contaminated areas. Journal of Radiological Protection, 39(1), 161-175. https://doi.org/10.1088/13616498/aaf6ca

\section{General rights}

Copyright and moral rights for the publications made accessible in the public portal are retained by the authors and/or other copyright owners and it is a condition of accessing publications that users recognise and abide by the legal requirements associated with these rights.

- Users may download and print one copy of any publication from the public portal for the purpose of private study or research.

- You may not further distribute the material or use it for any profit-making activity or commercial gain

- You may freely distribute the URL identifying the publication in the public portal

If you believe that this document breaches copyright please contact us providing details, and we will remove access to the work immediately and investigate your claim. 


\title{
Kerma conversion factors for modern glass buildings in radioactively contaminated areas
}

\author{
Y Hinrichsen, K G Andersson \\ Technical University of Denmark, Center for Nuclear Technologies, \\ Frederiksborgvej 399, 4000 Roskilde, Denmark \\ E-mail: yvhi@dtu.dk
}

\begin{abstract}
.
To improve the estimation of external gamma irradiation from deposited radioactivity in urban environments a model of a modern office or residential building with glass facades was set up with eleven different building heights. Kerma conversion factors for the floors inside the building from contamination on different types of surfaces were determined by using the Monte Carlo code MCNP6 for the primary gamma energies $0.3 \mathrm{MeV}, 0.662 \mathrm{MeV}$ and $3.0 \mathrm{MeV}$ and for three different environmental scenarios. The kerma conversion factors were expressed as formulas for each possible deposition area for contaminants. The importance of the determined factors was shown by comparing them to previously generally used factors for multistorey house blocks.
\end{abstract}

Submitted to: J. Radiol. Prot. 


\section{Introduction}

After an airborne release of radionuclides to inhabited environments, external gamma irradiation from deposited radioactivity can contribute considerably to the radiation exposure of the population (Golikov et al. 2002). The shielding of gamma radiation by buildings can, however, reduce this exposure and sheltering of inhabitants is one of the principal countermeasures considered for areas potentially affected by radioactive release. Detailed knowledge of the shielding properties of buildings is therefore an important component of risk assessment in radiological emergency preparedness.

As the geometry of building structures is too complex for simple methods such as the point kernel model (Spencer et al. 1980), Monte Carlo calculations are needed to calculate the kerma as shown in a comparison performed by Jensen \& Thykier-Nielsen (1989). The shielding properties and the resulting kerma rate can vary greatly for different types of buildings depending on the size of the building and its construction characteristics, on the energy spectrum of the radionuclides, on the distribution of the contaminants on the different surfaces and on the type of environment (e.g. Meckbach et al. 1988) leading to the use of Monte Carlo simulations in the late 1980s at the GSF (now the Helmholtz Zentrum München German Research Centre for Environmental Health) (Meckbach et al. 1988, Jacob \& Meckbach 1987, Meckbach \& Jacob 1988, Meckbach et al. 1987). An early Monte Carlo code SAM-CE (Lichtenstein et al. 1979) was applied to calculations for four different types of houses. Inhabited area external dose estimates in the European standard decision support systems ARGOS and RODOS rely entirely on these few old datasets. Monte Carlo calculations were repeated for the semi-detached house by Meckbach et al. (1988) using the modern code MCNP6 (Goorley et al. 2012), and similarities and deviations within the order of magnitude for different parts of the building are described in a paper that is still to be published (Hinrichsen \& Andersson 2018).

The applicability of the transport code MCNP6 in determining exposure reduction for a modular building type has been experimentally verified in a previous study by our group (Hinrichsen et al. 2018). Further Monte Carlo simulations were performed for an industrial area (Kis et al. 2003, Kis et al. 2004), for various scenarios of U.S. residential structures (Dickson \& Hamby 2014, Dickson \& Hamby 2016, Dickson et al. 2017), for typical houses in Brazil (Salinas et al. 2006), and typical buildings in Japan (Furuta \& Takahashi 2015). To the best of our knowledge such simulations have not previously been performed for buildings with glass facades that can be found in many cities now as a part of modern architecture or buildings with similar shielding properties. Therefore, the aim of this study was to set up a model of a modern glass building, derive the kerma conversion factors from different contaminated surfaces and compare them with the respective values that were derived for a multistorey house block (Meckbach et al. 1988) that would so far be applied in emergency management decision support for any high rise urban building.

\section{Materials and methods}

The Monte Carlo calculations for the setup of modern buildings were performed with the transport code MCNP6 (Goorley et al. 2012), using the nuclear cross-section data 
set ENDF/B-VII.0 (Chadwick et al. 2006). Among other processes, it accounts for photon creation and loss through relevant mechanisms such as bremsstrahlung, fluorescence, Compton scattering, photon capture, pair production and p-annihilation.

The code allows for the definition of complex 3-dimensional geometries through a combinatorial geometry technique. The definition of the geometry is leaned on the construction drawings and descriptions of a real glass building in the city of Copenhagen that were made available by the Technical and Environmental Administration of the Municipality of Copenhagen (Teknik- og Miljøforvaltning Københavns Kommune) and was applied to 11 different heights of the building from one storey till 11 storeys for a single house scenario that stands alone, for a park scenario with 3 houses in a row, and for a city scenario with a square of $3 \times 3$ houses (Figures 1 to 4 ). The outer walls are made of 2 layers of $1.2 \mathrm{~cm}$ thick glass with $97.6 \mathrm{~cm}$ air in between them. In the middle of the building (see Figures 1 and 2) is an atrium covered by a roof of $2.4 \mathrm{~cm}$ thick glass. It is not surround by any wall as it is usually surrounded by railings on the different floors. The house contains six shafts for stairs and elevators going from the basement up to the top of the building (see Figures 1 and 2). Their surrounding walls are made of $30 \mathrm{~cm}$ thick concrete. The building is furthermore based on sixty concrete columns (indicated by small circles in Figure 1) with a diameter of $60 \mathrm{~cm}$ going from the basement building. The intermediate floors and the roof are made $22 \mathrm{~cm}$ thick concrete and the basement is surrounded by $40 \mathrm{~cm}$ thick concrete to the bottom and to the sides. The spheres in Figures 1 to 4 indicate the positions of the tree canopies. As foliage on trees constitute a very efficient aerosol/rain filter, the contamination on the stem and braches will be of comparatively little importance (Roed 1988) and is not considered in the model.

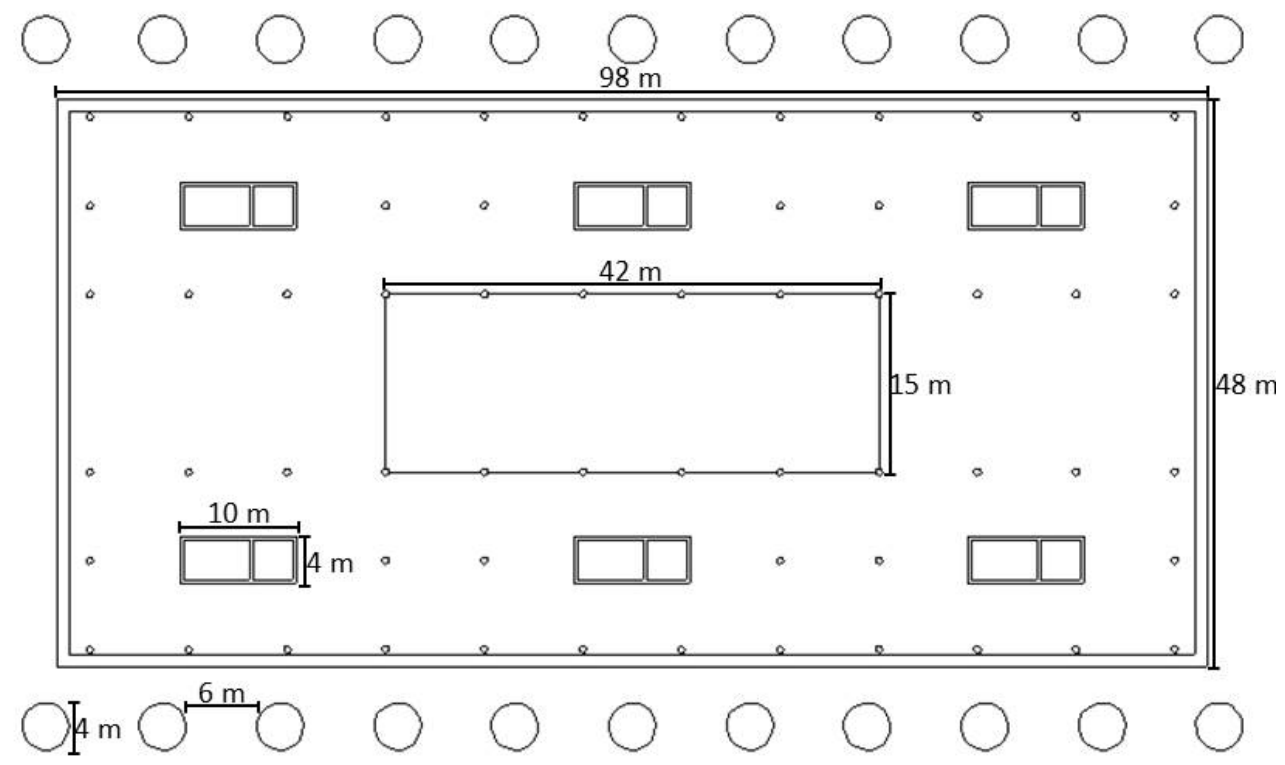

Figure 1. Horizontal cut of the glass building. 


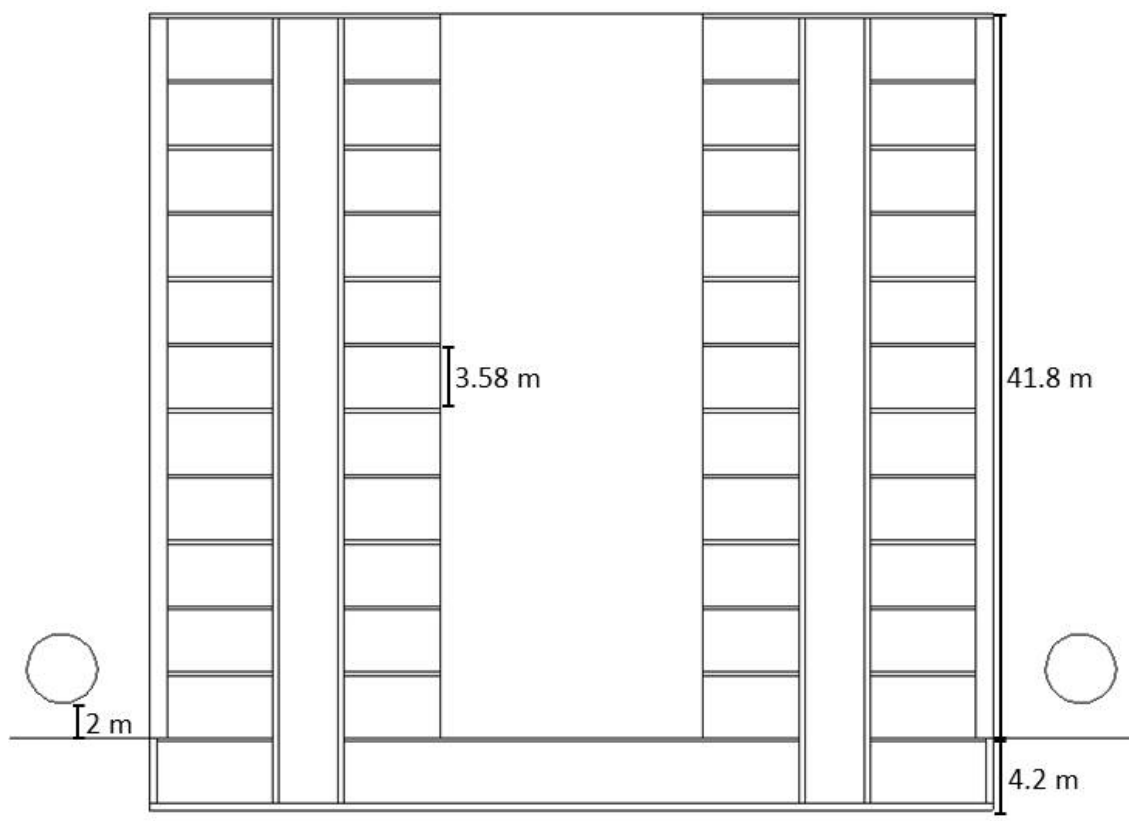

Figure 2. Vertical cut of the glass building for the largest height of eleven storeys.

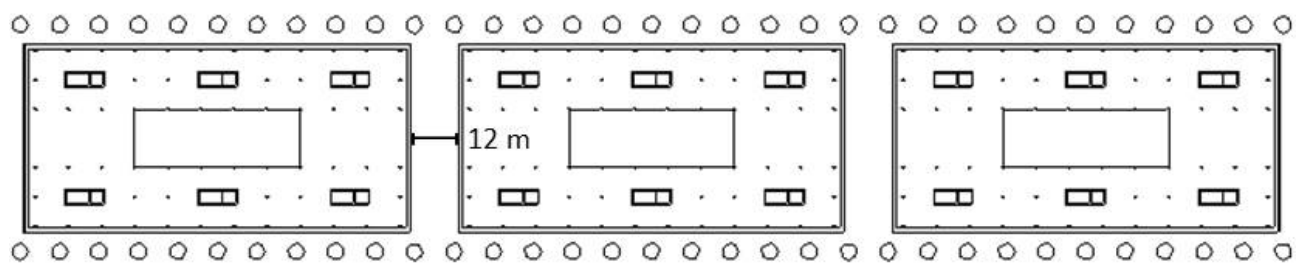

Figure 3. Horizontal cut of the park scenario.

The regions in space were constructed by a logical combination (union, intersection, difference) of elementary geometric bodies and surfaces. Data from a material compendium (McConn Jr et al. 2011) was used to assign the material specifications with definite atomic compositions and densities as summarized in Table 1 to the input for the different building structures and environmental regions.

Table 1. Material specifications with definite atomic compositions (rounded) and densities that were used for the Monte Carlo calculations.

\begin{tabular}{lll} 
Material & $\begin{array}{c}\text { densities that were used for the Monte Carlo calculations. } \\
\text { Atomic composition }\end{array}$ & Density in $\mathrm{kg} / \mathrm{l}$ \\
\hline Air & $0.02 \% \mathrm{C} ; 78.44 \% \mathrm{~N} ; 21.07 \% \mathrm{O} ; 0.47 \% \mathrm{Ar}$ & 0.001205 \\
Concrete & $8.47 \% \mathrm{H} ; 60.41 \% \mathrm{O} ; 1.25 \% \mathrm{Na} ; 2.48 \% \mathrm{Al} ; 24.19 \%$ & 2.25 \\
& $\mathrm{Si} ; 2.72 \% \mathrm{Ca}$; $0.47 \% \mathrm{Fe}$ & \\
Glass & $60.39 \% \mathrm{O} ; 8.81 \% \mathrm{Na} ; 25.18 \% \mathrm{Si} ; 5.62 \% \mathrm{Ca}$ & 2.4 \\
Soil & $31.69 \% \mathrm{H} ; 50.16 \% \mathrm{O} ; 4.00 \% \mathrm{Al} ; 14.16 \% \mathrm{Si}$ & 1.52 \\
\hline
\end{tabular}




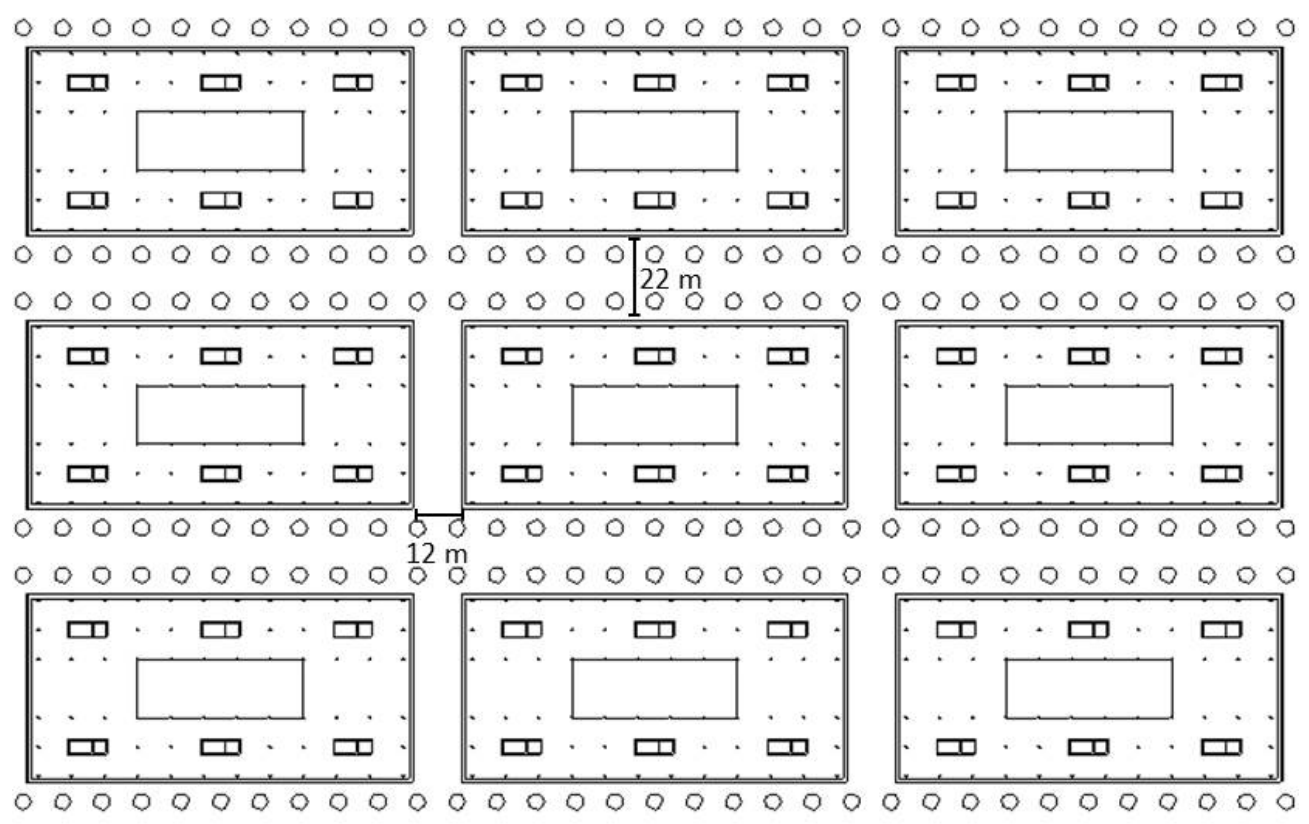

Figure 4. Horizontal cut of the city scenario.

For each height and scenario separate computations were performed for sources that were defined as surfaces on top of the ground, trees, walls, and roofs. The source energies were monoenergetic sources of $0.662 \mathrm{MeV}$ representing ${ }^{137} \mathrm{Cs}$, which has been of main concern regarding long term effects (Imanaka et al. 2015) in connection with the Chernobyl and Fukushima incidents, $0.3 \mathrm{MeV}$ or $3.0 \mathrm{MeV}$ to get an impression of the behaviour of the kerma for lower and higher primary gamma energies.

The detector regions were defined as air-filled spheres with a diameter of $30 \mathrm{~cm}$ and eighteen of them were positioned in various part of each floor $1 \mathrm{~m}$ above the level of the respective floor of the building. In those regions, the number and energies of the gamma 'particles' passing through were scored. By using conversion coefficients (ICRP 2010), the fluence was transferred to air kerma free-in-air and averaged over the eighteen detector regions in each floor. Furthermore, the code provides ten statistical tests that are performed on each defined detector region (called tally in MCNP). Those tests are a valuable tool to ascertain reliable statistical quality of the respective results.

Internal walls inside the building were not modelled, because in these modern buildings they are not part of the building. They are usually made of gypsum (around $12 \mathrm{~cm}$ thick) and can be built up and removed quickly. To get an idea about their shielding effect extra simulations were performed leading to the results that the kerma will be reduced by a factor of 0.72 for a primary gamma energy of $0.3 \mathrm{MeV}$, by 0.77 for a primary gamma energy of $0.662 \mathrm{MeV}$ and by 0.86 for a primary gamma energy of $3.0 \mathrm{MeV}$ after passing one gypsum wall of $12 \mathrm{~cm}$ thickness. 


\section{Results and discussion}

\subsection{Kerma conversion factors}

With the Monte Carlo calculations the kerma (pGy) per emitted gamma photon $(\gamma)$ on the source was determined. This factor was multiplied with the size of the respective source area $\left(\mathrm{mm}^{2}\right)$ to determine the kerma (pGy) for a source strength of one gamma photon per unit area $\left(\gamma \mathrm{mm}^{-2}\right)$ represented by $K$. These values were used as a basis to fit a mathematical model for the kerma over them for each type of surface at a given floor $F$ inside a building of a height $H$ with the smallest possible deviations.

The following mathematical expressions describe the kerma for all floors of the glass building for all building heights, environmental scenarios, source energies and source areas. $\mathrm{H}$ represents in the equations the height in terms of number of storeys above ground level (excluding the basement there are $H+1$ storeys). $F$ represents the floor inside the building from $F=-1$ (basement) through $F=0$ (ground floor) to higher floors (e.g. $F=5$ is the fifth floor). $F$ is of course restricted by the height of the building $(\mathrm{FH})$. All equations determine the kerma (pGy) for a source strength of one gamma photon per unit area $\left(\gamma \mathrm{mm}^{-2}\right)(K)$. By multiplying this factor with a given contamination level $\left(\mathrm{Bq} \mathrm{mm}{ }^{-2}\right)$ and the number of photons per disintegration $(\gamma)$ of the respective gamma energy, the kerma rate contribution for each gamma energy emitted with determined kerma factors can be calculated. As the basement of the building is more shielded than the rest of the building, an extra equation is necessary for all contamination scenarios.

The development of the kerma per source strength inside a glass building caused by contamination on the roof can be described by Equation (1) with the values of the variables given in Table 2 . The variable $a$ expresses the kerma per source strength in the floor directly under the roof, the term $\exp \left(-b \cdot(H-F)^{c}\right)$ the decrease of the kerma with distance to the roof, and the term $\left(1+d \cdot \exp \left(-e \cdot F^{f}\right)\right)$ the backscattered radiation from the ground. The kerma in the basement decreases with the height of the building as the distance to the basement increases $\left(g \cdot \exp \left(-h \cdot H^{i}\right)\right)$.

$$
K(F, H)= \begin{cases}a \cdot \exp \left(-b \cdot(H-F)^{c}\right) \cdot\left(1+d \cdot \exp \left(-e \cdot F^{f}\right)\right), & \forall F \geq 0 \\ g \cdot \exp \left(-h \cdot H^{i}\right), & \forall F=-1\end{cases}
$$

Equation (2) with the values of the variables given in Table 3 describes the development of the kerma per source strength inside a glass building caused by contamination on the walls. The variable $a$ expresses the maximal kerma per source strength in a floor with several floors under and over it. The term $\left(1-b \cdot \exp \left(-c \cdot F^{d}\right)\right)$ expresses the decrease of the kerma because of decreasing distance to the ground and therefore smaller area of contaminated wall below this floor, and the term $\left(1-e \cdot \exp \left(-f \cdot(H-F)^{g}\right)\right)$ the same effect of decreasing distance towards the roof of the building. Furthermore, the term $\left(1-h \cdot \exp \left(-i \cdot H^{j}\right)\right)$ expresses the impact of the height of the building as the source area of the walls increases with height. The kerma in the basement increases with the height and source area of the building $\left(1-l \cdot \exp \left(-m \cdot H^{n}\right)\right)$ towards a maximum value of $k$. 
Table 2. Values of the variables in Equation (1) describing the kerma per source strength inside a glass building caused by contamination on the roof. ' $\mathrm{a}$ ' and ' $\mathrm{g}$ ' have the dimension pGy per $\gamma \mathrm{mm}^{-2}$. All other variables are dimensionless.

\begin{tabular}{llll} 
& $0.3 \mathrm{MeV}$ & $0.662 \mathrm{MeV}$ & $3.0 \mathrm{MeV}$ \\
\hline$a$ & 4.70 & 15.3 & 126 \\
$b$ & 0.80 & 1.05 & 1.33 \\
$c$ & 0.78 & 0.74 & 0.70 \\
$d$ & 0.11 & 0.073 & 0.018 \\
$e$ & 1.29 & 1.27 & 0.95 \\
$f$ & 1.03 & 0.63 & 0.30 \\
\hline$g$ & 0.040 & 0.39 & 14.6 \\
$h$ & 0.35 & 0.59 & 0.96 \\
$i$ & 0.87 & 0.69 & 0.60 \\
\hline
\end{tabular}

$K(F, H)= \begin{cases}a \cdot\left(1-b \cdot \exp \left(-c \cdot F^{d}\right)\right) \cdot\left(1-e \cdot \exp \left(-f \cdot(H-F)^{g}\right)\right) \cdot\left(1-h \cdot \exp \left(-i \cdot H^{j}\right)\right), & \forall F \geq 0 \\ k \cdot\left(1-l \cdot \exp \left(-m \cdot H^{n}\right)\right), & \forall F=-1\end{cases}$

Table 3. Values of the variables in Equation (2) describing the kerma per source strength inside a glass building caused by contamination on the walls. ' $a$ ' and ' $k$ ' have the dimension pGy per $\gamma \mathrm{mm}^{-2}$. All other variables are dimensionless.

\begin{tabular}{llll} 
& $0.3 \mathrm{MeV}$ & $0.662 \mathrm{MeV}$ & $3.0 \mathrm{MeV}$ \\
\hline$a$ & 17.0 & 36.7 & 132 \\
$b$ & 0.066 & 0.065 & 0.098 \\
$c$ & 1.76 & 2.64 & 1.41 \\
$d$ & 0.0064 & 0.45 & 0.87 \\
$e$ & 0.12 & 0.12 & 0.15 \\
$f$ & 1.84 & 1.92 & 1.62 \\
$g$ & 0.39 & 0.42 & 0.74 \\
$h$ & 0.096 & 0.037 & 0.025 \\
$i$ & 0.25 & 0.59 & 1.46 \\
$j$ & 0.60 & 0.71 & 0.86 \\
\hline$k$ & 0.040 & 0.30 & 7.42 \\
$l$ & 0.34 & 0.35 & 0.41 \\
$m$ & 1.40 & 2.38 & 1.63 \\
$n$ & 0.17 & 0.31 & 1.33 \\
\hline
\end{tabular}

The development of the kerma per source strength inside a glass building caused by contamination on the ground can be described by Equations (3) and (4) with the respective values of the variables given in Tables 4 to 6 depending on the environmental scenario. The variable $a$ represents the kerma at the ground floor and the term $\exp \left(-b \cdot F^{c}\right)$ the decrease of it towards the roof. In the scenarios with neighbouring buildings skyshine has an impact on the floors closest to the roof, which is expressed by the term $\left(1+d \cdot \exp \left(-e \cdot(H-F)^{f}\right)\right)$. The kerma in the basement is independent from the height of the buildings and therefore stable. It is expressed by the value $d$ in the scenario without neighbouring buildings and by the value $\mathrm{g}$ in the scenarios with 
neighbouring buildings.

$$
K(F, H)= \begin{cases}a \cdot \exp \left(-b \cdot F^{c}\right), & \forall F \geq 0 \\ d, & \forall F=-1\end{cases}
$$

Table 4. Values of the variables in Equation (3) describing the kerma per source strength inside a glass building caused by contamination on the ground for a single house without any neighbouring buildings. ' $a$ ' and ' $d$ ' have the dimension pGy per $\gamma \mathrm{mm}^{-2}$. ' $\mathrm{b}$ ' and 'c' are dimensionless.

\begin{tabular}{llll} 
& $0.3 \mathrm{MeV}$ & $0.662 \mathrm{MeV}$ & $3.0 \mathrm{MeV}$ \\
\hline$a$ & 41.1 & 115 & 572 \\
$b$ & 0.64 & 0.67 & 0.62 \\
$c$ & 0.51 & 0.53 & 0.58 \\
\hline$d$ & 0.019 & 0.093 & 0.63 \\
\hline
\end{tabular}

$$
K(F, H)= \begin{cases}a \cdot \exp \left(-b \cdot F^{c}\right) \cdot\left(1+d \cdot \exp \left(-e \cdot(H-F)^{f}\right)\right), & \forall F \geq 0 \\ g, & \forall F=-1\end{cases}
$$

Table 5. Values of the variables in Equation (4) describing the kerma per source strength inside a glass building caused by contamination on the ground for a house in a park scenario with two neighbouring buildings. ' $a$ ' and ' $g$ ' have the dimension pGy per $\gamma \mathrm{mm}^{-2}$. All other variables are dimensionless.

\begin{tabular}{llll} 
& $0.3 \mathrm{MeV}$ & $0.662 \mathrm{MeV}$ & $3.0 \mathrm{MeV}$ \\
\hline$a$ & 34.5 & 95.7 & 475 \\
$b$ & 0.70 & 0.73 & 0.69 \\
$c$ & 0.50 & 0.51 & 0.54 \\
$d$ & 0.035 & 0.026 & 0.015 \\
$e$ & 0.37 & 0.48 & 0.52 \\
$f$ & 1.88 & 1.51 & 1.33 \\
\hline$g$ & 0.017 & 0.082 & 0.55 \\
\hline
\end{tabular}

Table 6. Values of the variables in Equation (4) describing the kerma per source strength inside a glass building caused by contamination on the ground for a house in a city scenario with eight neighbouring buildings. ' $a$ ' and ' $\mathrm{g}$ ' have the dimension pGy per $\gamma \mathrm{mm}^{-2}$. All other variables are dimensionless.

\begin{tabular}{llll} 
& $0.3 \mathrm{MeV}$ & $0.662 \mathrm{MeV}$ & $3.0 \mathrm{MeV}$ \\
\hline$a$ & 23.8 & 61.5 & 267 \\
$b$ & 1.18 & 1.36 & 1.46 \\
$c$ & 0.49 & 0.48 & 0.49 \\
$d$ & 0.12 & 0.13 & 0.084 \\
$e$ & 0.60 & 0.68 & 0.88 \\
$f$ & 1.56 & 1.49 & 1.57 \\
\hline$g$ & 0.011 & 0.056 & 0.36 \\
\hline
\end{tabular}

Neighbouring buildings contribute to the kerma by contamination on their roofs and walls. Equation (5) with the respective values of the variables given in Tables 7 
and 8 describe the development of the kerma per source strength inside a glass building caused by contamination on the roofs of those neighbouring buildings. The variable $a$ expresses the kerma per source strength in the floor directly under the roof, the term $\exp \left(-b \cdot(H-F)^{c}\right)$ the decreasing of the kerma with distance to the roof, and the term $\left(1+d \cdot \exp \left(-e \cdot F^{f}\right)\right)$ the backscattered radiation from the ground. The kerma in the basement decreases with the height of the building as the distance to the basement increases $\left(g \cdot \exp \left(-h \cdot H^{i}\right)\right)$ for primary gamma energies of 0.3 and $0.662 \mathrm{MeV}$. For primary gamma energies of $3.0 \mathrm{MeV}$ an extra of $-j \cdot \exp \left(-k \cdot H^{l}\right)$ has to be added to model the development of the kerma in the basement for different heights of the buildings. This may reflect a second relevant factor apart from the distance of source and detector position. By looking at the direct line between source and detector position can be seen that the distance of soil that has to be crossed, before the radiation reaches the basement, decreases with increasing height of the building. Therefore, the kerma in the basement at the beginning increases with increasing distance to the source as this shielding effect seems to have a higher impact on the kerma development in these ranges than the distance to the source which additionally seems to be only relevant for higher energies.

$K(F, H)= \begin{cases}a \cdot \exp \left(-b \cdot(H-F)^{c}\right) \cdot\left(1+d \cdot \exp \left(-e \cdot F^{f}\right)\right), & \forall F \geq 0 \\ g \cdot \exp \left(-h \cdot H^{i}\right) & \forall F=-1(0.3 a n d 0.662 M e V) \\ g \cdot \exp \left(-h \cdot H^{i}\right)-j \cdot \exp \left(-k \cdot H^{l}\right) & \forall F=-1(3.0 M e V)\end{cases}$

Table 7. Values of the variables in Equation (5) describing the kerma per source strength inside a glass building caused by contamination on the roof of two neighbouring buildings in a park scenario. 'a', ' $\mathrm{g}$ ' and ' $\mathrm{j}$ ' have the dimension pGy per $\gamma \mathrm{mm}^{-2}$. All other variables are dimensionless.

\begin{tabular}{llll} 
& $0.3 \mathrm{MeV}$ & $0.662 \mathrm{MeV}$ & $3.0 \mathrm{MeV}$ \\
\hline$a$ & 0.37 & 0.64 & 1.38 \\
$b$ & 0.74 & 0.84 & 0.70 \\
$c$ & 0.59 & 0.58 & 0.79 \\
$d$ & 0.034 & 0.039 & 0.039 \\
$e$ & 0.017 & 0.31 & 0.37 \\
$f$ & 4.95 & 1.78 & 1.45 \\
\hline$g$ & 0.00043 & 0.0018 & 0.077 \\
$h$ & 0.45 & 0.38 & 0.10 \\
$i$ & 0.90 & 0.85 & 1.61 \\
$j$ & - & - & 0.067 \\
$k$ & - & - & 0.20 \\
$l$ & - & - & 2.38 \\
\hline
\end{tabular}

The development of the kerma per source strength inside a glass building caused by contamination on the walls of neighbouring buildings can be described by Equation (2) with the respective values of the variables given in Tables 9 and 10 depending on the environmental scenario. The variable $a$ expresses the maximal kerma per source strength in a floor with several floors under and over it. The term $\left(1-b \cdot \exp \left(-c \cdot F^{d}\right)\right)$ expresses the decrease of the kerma because of decreasing distance to the ground 
Table 8. Values of the variables in Equation (5) describing the kerma per source strength inside a glass building caused by contamination on the roof of eight neighbouring buildings in a city scenario. ' $a$ ', 'g' and ' $j$ ' have the dimension pGy per $\gamma \mathrm{mm}^{-2}$. All other variables are dimensionless.

\begin{tabular}{llll} 
& $0.3 \mathrm{MeV}$ & $0.662 \mathrm{MeV}$ & $3.0 \mathrm{MeV}$ \\
\hline$a$ & 1.48 & 2.64 & 5.53 \\
$b$ & 0.55 & 0.61 & 0.52 \\
$c$ & 0.85 & 0.85 & 0.93 \\
$d$ & 0.063 & 0.066 & 0.037 \\
$e$ & 0.67 & 0.39 & 0.57 \\
$f$ & 1.56 & 1.91 & 1.26 \\
\hline$g$ & 0.0014 & 0.0079 & 0.39 \\
$h$ & 0.072 & 0.32 & 0.12 \\
$i$ & 1.78 & 0.96 & 1.26 \\
$j$ & - & - & 0.36 \\
$k$ & - & - & 0.16 \\
$l$ & - & - & 1.44 \\
\hline
\end{tabular}

and therefore less area of contaminated walls on this side of the floor, and the term $\left(1-e \cdot \exp \left(-f \cdot(H-F)^{g}\right)\right)$ the same effect of decreasing distance towards the roof of the buildings. Furthermore, the term $\left(1-h \cdot \exp \left(-i \cdot H^{j}\right)\right)$ expresses the impact of the heights of the buildings as the source area of the walls increases with height. The kerma in the basement increases with the height and source area of the building $\left(1-l \cdot \exp \left(-m \cdot H^{n}\right)\right)$ towards a maximum value of $k$.

Table 9. Values of the variables in Equation (2) describing the kerma per source strength inside a glass building caused by contamination on the walls of two neighbouring buildings in a park scenario. ' $a$ ' and ' $k$ ' have the dimension pGy per $\gamma \mathrm{mm}^{-2}$. All other variables are dimensionless.

\begin{tabular}{llll} 
& $0.3 \mathrm{MeV}$ & $0.662 \mathrm{MeV}$ & $3.0 \mathrm{MeV}$ \\
\hline$a$ & 4.62 & 10.8 & 36.9 \\
$b$ & 0.21 & 0.20 & 0.20 \\
$c$ & 1.11 & 1.34 & 1.52 \\
$d$ & 0.75 & 0.70 & 0.44 \\
$e$ & 0.38 & 0.40 \\
$f$ & 0.37 & 0.94 & 0.99 \\
$g$ & 0.89 & 1.19 & 1.13 \\
$h$ & 1.20 & 0.46 & 0.31 \\
$i$ & 0.51 & 0.51 & 0.74 \\
$j$ & 0.45 & 0.40 & 0.43 \\
\hline$k$ & 0.55 & 0.053 & 1.61 \\
$l$ & 0.0071 & 0.94 & 0.98 \\
$m$ & 0.92 & 0.15 & 0.11 \\
$n$ & 0.19 & 1.60 & 1.88 \\
\hline
\end{tabular}

Equation (6) with the respective values of the variables given in Tables 11 to 13 describe the development of the kerma per source strength inside a glass building 
Table 10. Values of the variables in Equation (2) describing the kerma per source strength inside a glass building caused by contamination on the walls of eight neighbouring buildings in a city scenario. ' $a$ ' and ' $k$ ' have the dimension pGy per $\gamma \mathrm{mm}^{-2}$. All other variables are dimensionless.

\begin{tabular}{llll} 
& $0.3 \mathrm{MeV}$ & $0.662 \mathrm{MeV}$ & $3.0 \mathrm{MeV}$ \\
\hline$a$ & 15.3 & 36.4 & 142 \\
$b$ & 0.23 & 0.22 & 0.22 \\
$c$ & 0.85 & 1.02 & 1.06 \\
$d$ & 0.90 & 0.99 & 1.07 \\
$e$ & 0.41 & 0.43 & 0.47 \\
$f$ & 0.51 & 0.51 & 0.50 \\
$g$ & 1.11 & 1.15 & 1.07 \\
$h$ & 0.61 & 0.56 & 0.46 \\
$i$ & 0.41 & 0.47 & 0.66 \\
$j$ & 0.69 & 0.64 & 0.62 \\
\hline$k$ & 0.024 & 0.24 & 6.42 \\
$l$ & 0.94 & 0.97 & 0.99 \\
$m$ & 0.079 & 0.061 & 0.039 \\
$n$ & 1.47 & 1.40 & 1.73 \\
\hline
\end{tabular}

caused by contamination on trees depending on the environmental scenario. The term $a \cdot \exp \left(-b \cdot F^{c}\right)$ describes the decreasing of the kerma with distance to the trees for buildings of heights $H \geq 1$ at the floors $F \geq 1$. The value of the variable $d$ expresses the kerma at the ground floor for a building height of $H=0$ and $e$ the kerma at the ground floor for higher buildings. The kerma in the basement is independent from the height of the buildings and expressed by the value $f$.

$$
K(F, H)= \begin{cases}a \cdot \exp \left(-b \cdot F^{c}\right), & \forall F, H \geq 0 \\ d & \forall F, H=0 \\ e & \forall F=0 \wedge H \geq 1 \\ f & \forall F=-1\end{cases}
$$

Table 11. Values of the variables in Equation (6) describing the kerma per source strength inside a glass building caused by contamination on trees for a single house without any neighbouring buildings. 'a', 'd', 'e' and ' $\mathrm{f}$ ' have the dimension pGy per $\gamma \mathrm{mm}^{-2}$. 'b' and 'c' are dimensionless.

\begin{tabular}{llll} 
& $0.3 \mathrm{MeV}$ & $0.662 \mathrm{MeV}$ & $3.0 \mathrm{MeV}$ \\
\hline$a$ & $1.42 \cdot 10^{17}$ & $6.50 \cdot 10^{9}$ & $1.12 \cdot 10^{10}$ \\
$b$ & 39.4 & 21.6 & 20.8 \\
$c$ & 0.048 & 0.10 & 0.12 \\
\hline$d$ & 1.07 & 2.66 & 10.2 \\
$e$ & 1.12 & 2.77 & 10.6 \\
$f$ & 0.0020 & 0.014 & 0.38 \\
\hline
\end{tabular}


Table 12. Values of the variables in Equation (6) describing the kerma per source strength inside a glass building caused by contamination on trees for a house in a park scenario with two neighbouring buildings. ' $a$ ', ' $d$ ', 'e' and ' $f$ ' have the dimension pGy per $\gamma \mathrm{mm}^{-2}$. ' $\mathrm{b}$ ' and 'c' are dimensionless.

\begin{tabular}{llll} 
& $0.3 \mathrm{MeV}$ & $0.662 \mathrm{MeV}$ & $3.0 \mathrm{MeV}$ \\
\hline$a$ & $4.24 \cdot 10^{18}$ & $3.58 \cdot 10^{9}$ & $3.90 \cdot 10^{42}$ \\
$b$ & 42.7 & 20.9 & 95.6 \\
$c$ & 0.041 & 0.095 & 0.025 \\
\hline$d$ & 1.19 & 2.98 & 11.7 \\
$e$ & 1.23 & 3.09 & 12.1 \\
$f$ & 0.0020 & 0.015 & 0.39 \\
\hline
\end{tabular}

Table 13. Values of the variables in Equation (6) describing the kerma per source strength inside a glass building caused by contamination on trees for a house in a city scenario with eight neighbouring buildings. ' $a$ ', ' $d$ ', 'e' and ' $f$ ' have the dimension pGy per $\gamma \mathrm{mm}^{-2}$. 'b' and 'c' are dimensionless.

\begin{tabular}{llll} 
& $0.3 \mathrm{MeV}$ & $0.662 \mathrm{MeV}$ & $3.0 \mathrm{MeV}$ \\
\hline$a$ & $4.70 \cdot 10^{20}$ & $3.01 \cdot 10^{9}$ & $9.10 \cdot 10^{9}$ \\
$b$ & 47.0 & 20.3 & 20.0 \\
$c$ & 0.030 & 0.078 & 0.092 \\
\hline$d$ & 1.78 & 4.55 & 18.6 \\
$e$ & 1.83 & 4.65 & 18.9 \\
$f$ & 0.0025 & 0.017 & 0.41 \\
\hline
\end{tabular}

\subsection{Comparison with previous values for a multistorey house block}

To show the relevance of the determined kerma factors they were compared to respective factors calculated by Meckbach et al. (1988) for a multistorey house block, which is the closest of the building models that were developed so far compared to the glass building model in this study. The multistorey house was five storeys high and therefore the values are compared to the values of the glass building with a height of $H=4$. Furthermore, kerma factors inside the multistorey house block were determined for the basement $(F=-1)$, the ground floor $(F=0)$, the second floor $(F=2)$, and the fourth floor $(F=4)$ and thus compared to the respective floors inside the glass building. Regarding the source areas on the building both factors for the roof were compared as well as the factor for the walls of the glass building with the sum of the factors for walls and windows of the multistorey house block. In case of the ground as source area the respective factors were compared for the park and the city scenario that were for the multistorey house block the sum of the factors for the street and the park in the park scenario and the factor for the street in case of the city scenario. For the neighbouring buildings (Meckbach et al. 1988) calculated factors for walls and windows as well as for the roof and for both park and city scenario. Therefore, all four could directly be compared to the respective ones determined for the glass building. Regarding the factors for the trees the respective ones for a park scenario were compared.

The comparison took place by dividing the factor for the glass building by the respective one for the multistorey house block for all values available. This was per- 
formed for all three primary gamma energies and the resulting ratios are presented in Tables 14 to 16.

Table 14. Ratios of the kerma factor for the glass building divided by the respective factor for a multistorey house block (Meckbach et al. 1988). The figures are given according to source and detection area for a primary gamma energy of $0.3 \mathrm{MeV}$.

\begin{tabular}{|c|c|c|c|c|}
\hline & Basement & $\begin{array}{l}\text { Ground } \\
\text { floor }\end{array}$ & $\begin{array}{l}\text { Second } \\
\text { floor }\end{array}$ & $\begin{array}{l}\text { Forth } \\
\text { floor }\end{array}$ \\
\hline \multicolumn{5}{|l|}{ On the building: } \\
\hline Roof & - & - & - & 7.85 \\
\hline Walls and windows & 12.3 & 4.39 & 4.49 & 4.38 \\
\hline \multicolumn{5}{|l|}{ Ground: } \\
\hline Park scenario (street and park) & 7.65 & 11.6 & 9.42 & 8.14 \\
\hline City scenario (street) & 2.76 & 24.1 & 21.6 & 30.2 \\
\hline \multicolumn{5}{|l|}{ Neighbouring buildings: } \\
\hline Roofs in a park scenario & - & 2.25 & 2.88 & 3.68 \\
\hline Roofs in a city scenario & - & 24.3 & 11.6 & 4.90 \\
\hline Walls and windows in a park scenario & 1.62 & 4.16 & 4.91 & 5.83 \\
\hline Walls and windows in a city scenario & 1.19 & 4.46 & 5.55 & 6.34 \\
\hline \multicolumn{5}{|l|}{ Trees: } \\
\hline Park scenario & 0.510 & 1.90 & 2.25 & 2.02 \\
\hline
\end{tabular}

Table 15. Ratios of the kerma factor for the glass building divided by the respective factor for a multistorey house block (Meckbach et al. 1988). The figures are given according to source and detection area for a primary gamma energy of $0.662 \mathrm{MeV}$.

\begin{tabular}{|c|c|c|c|c|}
\hline & Basement & $\begin{array}{l}\text { Ground } \\
\text { floor }\end{array}$ & $\begin{array}{l}\text { Second } \\
\text { floor }\end{array}$ & $\begin{array}{l}\text { Forth } \\
\text { floor }\end{array}$ \\
\hline \multicolumn{5}{|l|}{ On the building: } \\
\hline Roof & - & - & 271 & 4.04 \\
\hline Walls and windows & 17.5 & 3.94 & 4.20 & 3.77 \\
\hline \multicolumn{5}{|l|}{ Ground: } \\
\hline Park scenario (street and park) & 4.88 & 11.0 & 8.62 & 8.66 \\
\hline City scenario (street) & 2.83 & 23.9 & 21.1 & 35.4 \\
\hline \multicolumn{5}{|l|}{ Neighbouring buildings: } \\
\hline Roofs in a park scenario & - & 1.86 & 2.09 & 2.55 \\
\hline Roofs in a city scenario & - & 4.36 & 5.82 & 4.37 \\
\hline Walls and windows in a park scenario & 1.77 & 3.47 & 4.12 & 5.95 \\
\hline Walls and windows in a city scenario & 2.06 & 4.25 & 4.72 & 5.62 \\
\hline \multicolumn{5}{|l|}{ Trees: } \\
\hline Park scenario & 1.14 & 1.71 & 2.06 & 1.88 \\
\hline
\end{tabular}

The numbers show that the kerma factor is larger, apart from nine cases for the glass building than for the multistorey house block. Two extreme cases were determined with a ratio of 271 for the roof to second floor factor for a primary gamma energy of $0.662 \mathrm{MeV}$ and with a ratio of 383 for the roof to ground floor factor for a 
Table 16. Ratios of the kerma factor for the glass building divided by the respective factor for a multistorey house block (Meckbach et al. 1988). The figures are given according to source and detection area for a primary gamma energy of $3.0 \mathrm{MeV}$.

\begin{tabular}{|c|c|c|c|c|}
\hline & Basement & $\begin{array}{l}\text { Ground } \\
\text { floor }\end{array}$ & $\begin{array}{l}\text { Second } \\
\text { floor }\end{array}$ & $\begin{array}{l}\text { Forth } \\
\text { floor }\end{array}$ \\
\hline \multicolumn{5}{|l|}{ On the building: } \\
\hline Roof & - & 383 & 27.7 & 2.26 \\
\hline Walls and windows & 16.5 & 2.37 & 2.45 & 2.24 \\
\hline \multicolumn{5}{|l|}{ Ground: } \\
\hline Park scenario (street and park) & 2.03 & 6.13 & 4.74 & 5.06 \\
\hline City scenario (street) & 1.14 & 11.2 & 9.47 & 16.3 \\
\hline \multicolumn{5}{|l|}{ Neighbouring buildings: } \\
\hline Roofs in a park scenario & 0.223 & 0.250 & 0.319 & 0.649 \\
\hline Roofs in a city scenario & 0.412 & 0.838 & 1.27 & 1.64 \\
\hline Walls and windows in a park scenario & 1.08 & 1.93 & 2.27 & 2.02 \\
\hline Walls and windows in a city scenario & 1.39 & 2.98 & 3.19 & 3.21 \\
\hline \multicolumn{5}{|l|}{ Trees: } \\
\hline Park scenario & 1.93 & 1.21 & 0.635 & 0.665 \\
\hline
\end{tabular}

primary gamma energy of $3.0 \mathrm{MeV}$. The other ratios vary between 0.22 and 35.4 with an averaged ratio and standard error of the mean of $6.11 \pm 0.73$ (excluding the two extreme values).

Looking into the details the average ratio over each primary gamma energy decreases with increasing primary energy excluding the two extreme values as the averaged values are $7.72 \pm 1.34$ for a primary gamma energy of $0.3 \mathrm{MeV}, 6.76 \pm 1.36$ for a primary gamma energy of $0.662 \mathrm{MeV}$ and $4.05 \pm 0.99$ for a primary gamma energy of 3.0 MeV. Looking at the source areas of course the roof of the building has the highest averaged ratio because of the two extreme values with $116 \pm 77$ (without them it is still $10.5 \pm 5.1$ ). This source area in term of the averaged ratio is followed by the ground in the city scenario with $16.7 \pm 3.2$, the ground in the park scenario with $7.32 \pm 0.78$, the walls and windows of the building with $6.54 \pm 1.54$, the roofs of neighbouring buildings in the city scenario with $5.95 \pm 2.18$, the walls and windows of neighbouring buildings in the city scenario with $3.75 \pm 0.47$, the walls and windows of neighbouring buildings in the park scenario with $3.26 \pm 0.48$, the roofs of neighbouring buildings in the park scenario with $1.67 \pm 0.38$ and at last the trees in the park scenario with $1.49 \pm 2.18$. The averaging of the ratio over the detection areas excluding the two extreme values shows less variety with the values for ground floor $(6.60 \pm 1.49)$, second floor $(6.70 \pm 1.38)$ and fourth floor $(6.65 \pm 1.56)$ being similar. Only the basement shew a lower averaged ratio of $4.04 \pm 1.12$.

Apart from the building material, the deviations of the two building models are caused e.g. by different building sizes. Furthermore, the glass building had an atrium instead of a courtyard inside multistorey house block and the multistorey house block had light-shafts to the basement apart from the glass building. Moreover, the calculations were performed with different code, but the influence is further described in a paper that is still to be published (Hinrichsen \& Andersson 2018). Finally, those ratios 
underpin the importance of the determined factors for decision support systems as the kerma factors for the multistorey house block were calculated for only one building height.

\section{Conclusions}

The knowledgebase for external dose estimations in inhabited areas was improved by determining kerma conversion factors for a modern glass building that can be found in a similar way in many modern cities now. Therefore, those factors support the progress of decision making in modern cities regarding managing the long term consequences of an airborne release of radionuclides as e.g. a nuclear power plant accident. The description as formulas allows the further application of the glass building model regardless of the height of the building and detection area. Furthermore, the importance of this building model was shown by comparing its results for kerma factors with those calculated by Meckbach et al. (1988) for a multistorey house block. The results of this comparison show the importance of taking into account adequate representations of construction geometries and materials when estimating kerma. The kerma conversion factors are given in a format that can in practice readily be implemented in the European decision support systems for management of the radiological consequences of airborne urban contamination.

\section{References}

Chadwick, M., Obložinský, P., Herman, M., Greene, N., McKnight, R., Smith, D., Young, P., MacFarlane, R., Hale, G., Frankle, S., Kahler, A., Kawano, T., Little, R., Madland, D., Moller, P., Mosteller, R., Page, P., Talou, P., Trellue, H., White, M., Wilson, W., Arcilla, R., Dunford, C., Mughabghab, S., Pritychenko, B., Rochman, D., Sonzogni, A., Lubitz, C., Trumbull, T., Weinman, J., Brown, D., Cullen, D., Heinrichs, D., McNabb, D., Derrien, H., Dunn, M., Larson, N., Leal, L., Carlson, A., Block, R., Briggs, J., Cheng, E., Huria, H., Zerkle, M., Kozier, K., Courcelle, A., Pronyaev, V. \& van der Marck, S. (2006), 'Endf/b-vii.0: Next generation evaluated nuclear data library for nuclear science and technology', Nuclear Data Sheets 107(12), 2931 - 3060. Evaluated Nuclear Data File ENDF/B-VII.0.

Dickson, E. D. \& Hamby, D. M. (2014), 'Cloud immersion building shielding factors for us residential structures', Journal of Radiological Protection 34(4), 853-871.

Dickson, E. D. \& Hamby, D. M. (2016), 'Building protection- and building shielding-factors for environmental exposure to radionuclides and monoenergetic photon emissions', Journal of Radiological Protection 36(3), 579-615.

Dickson, E. D., Hamby, D. M. \& Eckerman, K. F. (2017), 'Contaminant deposition building shielding factors for us residential structures (vol 35, pg 317, 2015)', Journal of Radiological Protection 37(4), 961-962.

Furuta, T. \& Takahashi, F. (2015), 'Study of radiation dose reduction of buildings of different sizes and materials', Journal of Nuclear Science and Technology 52(6), 897-904.

Golikov, V., Balonov, M. \& Jacob, P. (2002), 'External exposure of the population living in areas of russia contaminated due to the chernobyl accident', Radiation and Environmental Biophysics 41(3), 185-193.

Goorley, T., James, M., Booth, T., Brown, F., Bull, J., Cox, L. J., Durkee, J., Elson, J., Fensin, M., Forster, R. A., Hendricks, J., Hughes, H. G., Johns, R., Kiedrowski, B., Martz, R., Mashnik, S., McKinney, G., Pelowitz, D., Prael, R., Sweezy, J., Waters, L., Wilcox, T. \& Zukaitis, T. (2012), 'Initial mcnp6 release overview', Nuclear Technology 180(3), 298-315.

Hinrichsen, Y. \& Andersson, K. G. (2018), 'European decision support modelling of longterm external doses received in inhabited areas contaminated by a nuclear power plant accident - 1: initial relative dose rate contributions from different contaminated outdoor surfaces (working title)', to be published. 
Hinrichsen, Y., Finck, R., Östlund, K., Rääf, C. \& Andersson, K. G. (2018), 'Comparison of experimental and calculated shielding factors for modular buildings in a radioactive fallout scenario', Journal of Environmental Radioactivity 189, 146 - 155.

ICRP (2010), 'Conversion coefficients for radiological protection quantities for external radiation exposures', Annals of the ICRP 40(2), 1 - 257. ICRP Publication 116.

Imanaka, T., Hayashi, G. \& Endo, S. (2015), 'Comparison of the accident process, radioactivity release and ground contamination between chernobyl and fukushima-1', Journal of Radiation Research 56(Suppl. 1, Sp. Iss. SI), I56-I61.

Jacob, P. \& Meckbach, R. (1987), 'Shielding factors and external dose evaluation', Radiation Protection Dosimetry 21(1-3), 79-85.

Jensen, P. H. \& Thykier-Nielsen, S. (1989), 'Shielding factor calculation for plume radiation', Radiation Protection Programme. Progress Report 1988 pp. 1561-1565.

Kis, Z., Eged, K., Meckbach, R. \& Müller, H. (2003), 'Guidelines for planning interventions against external exposure in industrial area after a nuclear accident. pt. 2. calculation of doses using monte carlo method. institut für strahlenschutz, gsf - forschungszentrum für umwelt und gesundheit gmbh'.

Kis, Z., Eged, K., Voigt, G., Meckbach, R. \& Müller, H. (2004), 'Modeling of an industrial environment: External dose calculations based on monte carlo simulations of photon transport', Health Physics 86(2), 161-173.

Lichtenstein, H., Cohen, M., Steinberg, H., Troubetzkoy, E. \& Beer, M. (1979), 'The sam-ce monte carlo system for radiation transport and criticality calculations in complex configurations (revision 7.0). mathematical application group, inc.'.

McConn Jr, R., Gesh, C., Pagh, R., Rucker, R. \& Williams III, R. (2011), 'Radiation portal monitor project - compendium of material composition data for radiation transport modeling. pacific northwest national laboratory. piet-43741-tm-963, pnnl-15870 rev. 1'.

Meckbach, R. \& Jacob, P. (1988), 'Gamma exposures due to radionuclides deposited in urban environments. part ii: Location factors for different deposition patterns', Radiation Protection Dosimetry 25(3), 181-190.

Meckbach, R., Jacob, P. \& Paretzke, H. (1988), 'Gamma exposures due to radionuclides deposited in urban environments. part i: Kerma rates from contaminated urban surfaces', Radiation Protection Dosimetry 25(3), 167-179.

Meckbach, R., Jacob, P. \& Paretzke, H. G. (1987), 'Shielding of gamma radiation by typical european houses', Nuclear Instruments and Methods in Physics Research Section A: Accelerators, Spectrometers, Detectors and Associated Equipment 255(1), 160 - 164.

Roed, J. (1988), 'The distribution on trees of dry deposited material from the chernobyl accident', Joint Cec/oecd(nea) Workshop on Recent Advances in Reactor Accident Consequence Assessment. Proceedings of the Second Part of the Workshop (eur 11408 En) pp. 165-78, $165-178$.

Salinas, I. C. P., Conti, C. C., Rochedo, E. R. R. \& Lopes, R. T. (2006), 'Gamma shielding factor for typical houses in brazil', Radiation Protection Dosimetry 121(4), 420-424.

Spencer, L. V., Chilton, A. B. \& Eisenhauer, C. M. (1980), 'Structure shielding against fallout gamma rays from nuclear detonations', National Bureau of Standards, Special Publication . 